\title{
Type A aortic dissection with arch entry tear: Surgical experience in 104 patients over a 12-year period
}

\author{
Wei-Guo Ma, MD, PhD, ${ }^{\text {a,b,c }}$ Wei Zhang, MD, ${ }^{\mathrm{a}}$ Long-Fei Wang, MD, ${ }^{\mathrm{a}}$ Jun Zheng, MD, PhD,,${ }^{\mathrm{a}, \mathrm{b}}$ \\ Bulat A. Ziganshin, MD, ${ }^{\mathrm{c}}$ Paris Charilaou, MD ${ }^{\mathrm{c}}$ Xu-Dong Pan, MD, ${ }^{\mathrm{a}, \mathrm{b}}$ Yong-Min Liu, MD, ${ }^{\mathrm{a}, \mathrm{b}}$ \\ Jun-Ming Zhu, MD, ${ }^{\mathrm{a}, \mathrm{b}}$ Qian Chang, MD, ${ }^{\mathrm{b}}$ John A. Rizzo, PhD, ${ }^{\mathrm{c}, \mathrm{d}, \mathrm{e}}$ John A. Elefteriades, MD, ${ }^{\mathrm{c}}$ and \\ Li-Zhong Sun, MD ${ }^{\text {,b }}$
}

\section{ABSTRACT}

Objective: To evaluate the efficacy of the frozen elephant trunk (FET) and total arch replacement (TAR) technique (FET + TAR) in the management of type A aortic dissection (TAAD) with arch entry tear.

Methods: Clinical outcomes were analyzed for 104 TAAD patients with arch entry tear undergoing FET + TAR at $4.7 \pm 3.5$ days from symptom onset and compared with 728 TAAD patients with entry tears in elsewhere. The mean patient age was $49.3 \pm 9.3$ years, compared with $45.6 \pm 10.8$ years in other TAAD patients $(P<.001)$. There were 84 men $(80.8 \%)$. Hypertension was seen in $84.6 \%(88 / 104)$.

Results: Operative mortality was $8.6 \%$ (9/104). Spinal cord injury occurred in 3 cases $(2.9 \%)$, stroke in $2(1.9 \%)$, renal failure in $4(3.8 \%)$ and limb ischemia in 2 $(1.9 \%)$. Follow-up was $100 \%(95 / 95)$ at mean $5.6 \pm 2.6$ years (range $1.3-11.6)$. Late death occurred in 2 cases $(1.9 \%)$. Survival and freedom from late adverse events were $89.2 \%$ (95\% confidence interval [CI], 81.3\%-93.9\%) and $85.0 \%$ ( $95 \%$ CI, $76.3 \%-90.8 \%$ ) at 8 years, respectively. Both the stented and unstented distal aortic segments showed significant trends of false lumen shrinkage and true lumen expansion over time $(P<.001)$. Of the $65 \mathrm{CT}$ scans at mean $4.6 \pm 2.9$ years postoperatively, the false lumen was completely obliterated in 63 . Risk factors for arch entry tear were hypertension (odds ratio [OR], 2.091; 95\% CI, 1.186-3.687; $P=.011)$ and age (OR, 1.025; 95\% CI, 1.002-1.048; $P=.032)$.

Conclusions: TAAD with arch entry tear was treated safely and durably by FET + TAR. Although patients with arch entry tear were somewhat older than other patients, operative mortality was not substantially higher despite their older age and arch location of entry tear. These results argue favorably for the use of the FET + TAR technique in the management of TAAD patients with arch entry tears. (J Thorac Cardiovasc Surg 2016;151:1581-92)

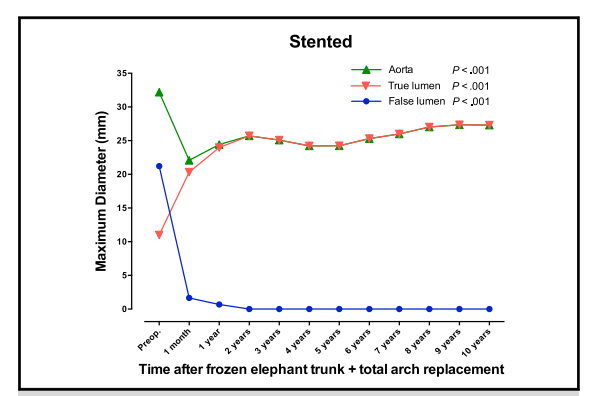

Following FET + TAR, the stented aortic segment showed significant temporal trends toward false lumen shrinkage and true lumen expansion.

\section{Central Message}

Acute aortic dissection with arch entry tear represents a higher level of complexity than patients with ascending aortic location of tear. This study finds very favorable results via total aortic arch replacement with frozen elephant trunk. This extensive surgical approach is recommended in such a setting.

\section{Perspective}

Aortic dissections with arch entry tear account for $12.5 \%$ of type A aortic dissections. Arch tears are most frequently located in the greater curvature. Patients in this series were somewhat older than those with an entry tear located elsewhere. The arch tear location makes the clinical situation more challenging. The rate of aortic valve resuspension was higher and rate of root replacement lower than patients with other type A dissections. Our satisfactory early and late outcomes argue favorably for the use of the frozen elephant trunk and total arch replacement technique in the management of patients with arch dissections.

See Editorial Commentary page 1593.

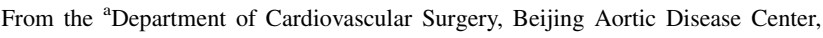
Beijing Anzhen Hospital of Capital Medical University, Beijing Institute of Heart, Lung and Blood Vessel Diseases, and Beijing Engineering Research Center of Vascular Prostheses, Beijing, China; ${ }^{\mathrm{b}} \mathrm{Fu}$ Wai Hospital and Cardiovascular Institute, Chinese Academy of Medical Sciences, Beijing, China; ${ }^{\mathrm{c}}$ Aortic Institute at Yale-New Haven, Yale University School of Medicine, New Haven, Conn; and Departments of ${ }^{\mathrm{d}}$ Economics and ${ }^{\mathrm{e}}$ Preventive Medicine, Stony Brook University, Stony Brook, NY.

Drs Zhang and Ma contributed equally to this work.

This study was supported in part by the National Key Technologies Research and Development Program (Grant 2015BA112B03) and the Special Research Fund for Public Health and Welfare (Grant 201402009).
}

Read at the 95th Annual Meeting of The American Association for Thoracic Surgery, Seattle, Washington, April 25-29, 2015.

Received for publication April 13, 2015; revisions received Nov 17, 2015; accepted for publication Nov 26, 2015; available ahead of print Feb 6, 2016.

Address for reprints: Li-Zhong Sun, MD, Department of Cardiovascular Surgery, Beijing Anzhen Hospital of Capital Medical University, 2 Anzhen Rd, Beijing 100029, China (E-mail: lizhongsun@outlook.com).

$0022-5223 / \$ 36.00$

Copyright (C) 2016 by The American Association for Thoracic Surgery http://dx.doi.org/10.1016/j.jtcvs.2015.11.056 


\section{Abbreviations and Acronyms \\ $\mathrm{CI}=$ confidence interval \\ $\mathrm{CPB}=$ cardiopulmonary bypass \\ $\mathrm{CT}=$ computed tomography \\ FET $=$ frozen elephant trunk \\ OR = odds ratio \\ TAAD $=$ type A aortic dissection \\ TAR $=$ total arch replacement}

Scanning this QR code will take you to the article title page. To view the AATS 2015 Webcast, see the URL at the end of the article.

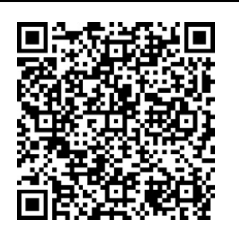

Aortic dissections originating from an entry tear located in the transverse arch represent a special entity that is not addressed by the most widely accepted Stanford and DeBakey classification schemes. ${ }^{1,2}$ Although relatively uncommon, these dissections occur with significant frequency, comprising $9 \%-31 \%$ of all aortic dissections. ${ }^{3,4}$ The optimal management of aortic dissections with arch entry tear, or "arch dissections," has generated much controversy. ${ }^{5}$ Most authors recommend surgical repair for aortic dissections with arch entry tear; however, the appropriate extent of resection is a matter of debate, and various surgical techniques have been reported, including isolated ascending aortic replacement (with a composite graft if needed), hemiarch replacement, total arch replacement (TAR), possible elephant trunk techniques, and even extra-anatomic bypass. ${ }^{6-22}$

The frozen elephant trunk (FET) technique is being increasingly used to repair aortic dissections involving the aortic arch and proximal descending aorta, and has improved clinical outcomes considerably. ${ }^{23,24}$ The general consensus is that the FET approach will achieve complete arch repair and reduce the need for subsequent reoperations, ${ }^{23}$ and there is some evidence to support this. Nonetheless, the optimal indications for this approach remain a matter of debate, ${ }^{24}$ as do the potentially increased risks of stroke and mortality. In addition, there are only limited data regarding the long-term outcomes of the FET technique, ${ }^{23,25,26}$ especially when performed in patients with arch entry tears. ${ }^{27,28}$

Over the past decade, we have performed FET and TAR using a 4-branched graft (ie, the Sun procedure ${ }^{29}$ ) in 104 consecutive patients with type A aortic dissection (TAAD) originating from an entry tear in the transverse aortic arch. The present study aimed to evaluate the efficacy of the Sun procedure in the management of arch dissections by analyzing early and late outcomes in this group of patients.

\section{METHODS}

The Ethics Committees of Fu Wai Hospital and Cardiovascular Institute and Beijing Anzhen Hospital, Capital Medical University approved this retrospective study.

\section{Patients}

Between April 2003 and November 2012, our group performed the Sun procedure in a total of 832 patients with TAAD. The mean patient age was $46.1 \pm 10.7$ years (range, 17-78 years), and the cohort was $79.8 \%$ male $(n=664)$. Based on the location of the primary entry tear, patients were divided into the "arch group," with an entry tear located in the transverse arch in 104 cases $(12.5 \%)$, and the "non-arch group" ( $\mathrm{n}=728)$, with an entry tear located elsewhere, including the ascending aorta in 366 cases $(44.0 \%)$, descending aorta in 211 cases $(25.4 \%)$, multiple in 90 cases $(10.8 \%)$ and unidentified in 61 cases $(7.3 \%)$ (Figure 1). In the arch group, the entry tear originated in the transverse arch, extending primarily proximally into the ascending aorta and often distally into the descending aorta. Patients with TAAD arising from an entry tear in the descending aorta with retrograde extension proximally into the arch and ascending aorta were excluded from the arch group.

The 104 patients with arch entry tear included 84 men (80.8\%) and had a mean age of $49.3 \pm 9.3$ years (range, 20-65 years), significantly older than the patients in the non-arch group (mean, $45.6 \pm 10.8$ years; $P<.001$ ). Sixteen patients $(15.4 \%$ ) were aged 60 years or older. Hypertension was more predominant in the arch group than in the non-arch group $(84.6 \%$ [88 of 104] vs $68.0 \%$ [496 of 728]; $P<.001$ ), whereas Marfan syndrome was identified in only 1 patient $(0.9 \%)$ of the arch group compared with 86 patients $(11.8 \%)$ in the non-arch group $(P<.001)$. Bicuspid aortic valve and isolated left vertebral artery were present in 4 cases each $(2.9 \%)$, and polycystic kidney disease was seen in 1 case $(0.9 \%)$. Preoperative malperfusion syndrome occurred in $10.6 \%$ of patients (11 of 104) in the arch group, compared with $10.7 \%$ (78 of 728 ) in the non-arch group $(P=.966)$.

Based on an interval between symptom onset and surgery of $\leq 14$ days, all TAADs with arch entry tear in this study were acute, repaired at a mean of $4.7 \pm 3.5$ days from symptom onset (median, 3.8 days; range, 5 hours to 14 days). In comparison, the TAADs in the non-arch group were repaired at a mean of 95.6 days from symptom onset (median, 14 days; range, 2 hours to 10 years; $P<.001$ ) (Table 1 ). The selection criteria for the Sun procedure in patients with TAAD have been described previously. ${ }^{29}$

\section{Surgical Techniques}

The surgical technique, known as the Sun procedure, ${ }^{29}$ has been described in detail previously. ${ }^{30,31}$ Specifically, right axillary artery cannulation is used for cardiopulmonary bypass (CPB) and unilateral selective antegrade cerebral perfusion under moderate hypothermic circulatory arrest at $25^{\circ} \mathrm{C}$. The flow rate of antegrade cerebral perfusion is $5-10 \mathrm{~mL} / \mathrm{kg} / \mathrm{min}$, and a mean perfusion pressure of $40-60 \mathrm{~mm} \mathrm{Hg}$ is maintained during CPB. A pressure of $\geq 20 \mathrm{~mm} \mathrm{Hg}$ in the left radial artery is considered sufficient for cerebral perfusion. The procedure involves deployment of an open stent graft (Cronus; MicroPort Medical, Shanghai, China) into the descending aorta, followed by TAR with a 4-branched vascular graft (Maquet Cardiovascular, Wayne, NJ). To minimize the duration of cerebral, myocardial, and spinal cord ischemia, distal reperfusion is initiated once the distal anastomosis is completed, and the left carotid artery is reconstructed first (after which rewarming is started and the brain is perfused bilaterally), followed by the ascending 


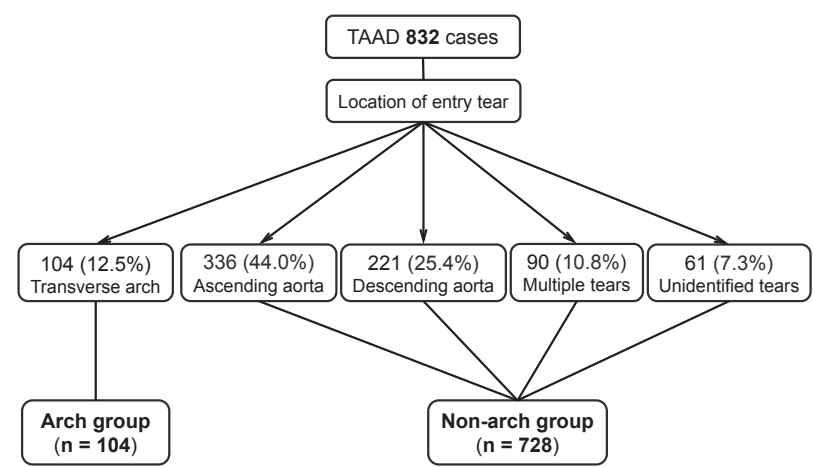

FIGURE 1. Flow diagram depicting patient groups based on location of the entry tear. TAAD, Type A aortic dissection.

aorta (to resume myocardial perfusion), then the left subclavian artery, and finally, the innominate artery.

\section{Patient Follow-up}

All operative survivors were followed up regularly through phone calls, e-mails, or letters. An annual computed tomography (CT) scan was recommended to detect thrombosis and obliteration of the false lumen; evaluate the size of the true lumen, false lumen, and stented and unstented distal aortic segments; and identify endoleak and other

TABLE 1. Preoperative clinical profiles

\begin{tabular}{|c|c|c|c|c|}
\hline Variable & $\begin{array}{c}\text { Total } \\
(\mathbf{n}=\mathbf{8 3 2})\end{array}$ & $\begin{array}{c}\text { Arch } \\
\text { group } \\
(\mathbf{n}=\mathbf{1 0 4})\end{array}$ & $\begin{array}{c}\text { Non-arch } \\
\text { group } \\
(\mathbf{n}=728)\end{array}$ & $\begin{array}{c}P \\
\text { value }\end{array}$ \\
\hline Age, year, mean $\pm S D$ & $46.1 \pm 10.7$ & $49.3 \pm 9.3$ & $45.6 \pm 10.8$ & $.001 *$ \\
\hline Gender, n $(\%)$ & & & & .794 \\
\hline Male & $664(79.8)$ & $84(80.8)$ & $580(79.7)$ & \\
\hline Female & $168(20.2)$ & $20(19.2)$ & $148(20.3)$ & \\
\hline Acuity, n (\%) & & & & $<.001$ \\
\hline $\begin{array}{r}\text { Acute }(\leq 14 \mathrm{~d} \\
\text { from onset })\end{array}$ & $473(56.9)$ & $104(100)$ & $369(50.7)$ & \\
\hline Chronic & $359(43.1)$ & $0(0)$ & $359(49.3)$ & \\
\hline \multicolumn{5}{|l|}{ Comorbidities, n (\%) } \\
\hline Hypertension & $583(70.1)$ & $88(84.6)$ & $495(68.0)$ & $<.001$ \\
\hline Marfan syndrome & $87(10.5)$ & $1(1.0)$ & $86(11.8)$ & $<.001$ \\
\hline Diabetes mellitus & $24(2.9)$ & $2(1.9)$ & $22(3.0)$ & .531 \\
\hline Coronary artery disease & $49(5.9)$ & $6(5.8)$ & $43(5.9)$ & .956 \\
\hline Cerebrovascular disease & $25(3.0)$ & $6(5.8)$ & $19(2.6)$ & .114 \\
\hline Chronic kidney disease & $20(2.4)$ & $2(1.9)$ & $18(2.5)$ & .999 \\
\hline $\begin{array}{l}\text { Malperfusion syndrome, } \\
\mathrm{n}(\%) \dagger\end{array}$ & $89(10.7)$ & $11(10.6)$ & $78(10.7)$ & .966 \\
\hline Cerebral & $21(2.5)$ & $3(2.9)$ & $18(2.5)$ & .738 \\
\hline Myocardial & $14(1.7)$ & $3(2.9)$ & $11(1.5)$ & .402 \\
\hline Renal & $7(0.8)$ & $1(1.0)$ & $6(0.8)$ & .999 \\
\hline Lower extremity & $49(5.9)$ & $4(3.8)$ & $45(6.2)$ & .344 \\
\hline Other & $23(2.8)$ & $0(0)$ & $23(3.1)$ & .100 \\
\hline Acute heart failure, $\mathrm{n}(\%)$ & $7(0.8)$ & $1(1.0)$ & $6(0.8)$ & .999 \\
\hline Cardiac tamponade, n $(\%)$ & $16(1.9)$ & $3(2.9)$ & $13(1.8)$ & .438 \\
\hline
\end{tabular}

complications. By March 2015, 65 patients had undergone follow-up CT scans $(68.4 \%)$.

\section{Statistical Analysis}

Data were analyzed using SPSS for Windows version 16.0 (SPSS, Chicago, Ill). Data are expressed as mean \pm standard deviation (SD) or number and percentage and were compared using the Student $t$ test or Pearson $\chi^{2}$ test for normal distributions and the Mann-Whitney $U$ test for abnormal distributions, as appropriate. Risk factors for arch entry tear and early adverse outcomes were identified with univariate and multivariate analyses. Changes in the true and false lumens of the stented and unstented distal aortic segments were evaluated with a linear mixed model. All statistical tests were 2 -sided, and a $P$ value of $<.05$ was considered statistically significant.

\section{RESULTS}

\section{Operative Data}

An arch entry tear was verified by a preoperative CT angiogram in 87 patients $(83.6 \%)$ and by intraoperative inspection in 17 patients $(16.4 \%)$. All entry tears were resected during surgical repair. Table 2 lists entry tear locations on the greater or lesser curvature and proximity to the orifices of arch vessels. The entry tear was located in the greater curvature in 55 cases $(52.9 \%)$, in the lesser curvature in 49 cases $(47.1 \%)$, between the left carotid and subclavian arteries in 20 cases $(19.2 \%)$, close to the left subclavian artery in 19 cases $(18.3 \%)$, and close to the innominate artery in 13 cases $(12.5 \%)$. Dissection involved the innominate artery in 65 cases $(62.5 \%)$, the left carotid artery in 48 cases $(46.1 \%)$, the left subclavian artery in 60 cases (57.7\%), all 3 arch vessels in 40 cases $(38.5 \%)$, and 2 arch vessels in 15 cases $(14.3 \%)$. The sinuses of Valsalva were involved in 64 cases $(61.5 \%)$, and the descending aorta was involved in 54 cases $(51.9 \%)$.

The mean length of the implanted open stent graft was $99.8 \pm 4.7 \mathrm{~mm}$ (range, $80-120 \mathrm{~mm}$ ) and the mean diameter was $26.8 \pm 1.2 \mathrm{~mm}$ (range, 24-30 mm). The mean duration of CPB was $196 \pm 47$ minutes, and that of cross-clamping was $114 \pm 78$ minutes. Mean selective antegrade cerebral perfusion time was significantly longer in the arch group $(28 \pm 11$ minutes vs $24 \pm 8$ minutes; $P=.007)$. Aortic valve resuspension was performed in $23.1 \%$ (24 of 104) of patients in the arch group, compared with $10.7 \%$ (78 of 728) of those in the non-arch group $(P<.001)$. Composite root replacement was required in $9.6 \%$ of patients ( 10 of $104)$ in the arch group versus $33.8 \%$ of those ( 246 of 728 ) in the non-arch group $(P<.001)$; among the latter, $70 \%(172$ of 246) had an entry tear located in the ascending aorta (Table 3). No patients in the arch group required an extra-anatomic bypass (eg, femoral-to-femoral, ascending aortic-to-femoral), which was performed in 28 patients $(3.8 \%)$ in the non-arch group $(P=.039)$. Concomitant coronary artery bypass grafting was performed in 10 patients $(9.6 \%)$, for dissection-related coronary ischemia in 6 and for preexisting coronary artery disease in 4 . 
TABLE 2. Locations of entry tears in the transverse arch

\begin{tabular}{lccc}
\hline \multicolumn{1}{c}{ Location } & Greater curvature $(\mathbf{n}=\mathbf{5 5 ;} \mathbf{5 2 . 8} \%)$ & Lesser curvature $(\mathbf{n}=\mathbf{4 9} ; \mathbf{4 7 . 2} \%)$ & Total $(\mathbf{n}=\mathbf{1 0 4} ; \mathbf{1 0 0} \%)$ \\
\hline Innominate artery & $7(6.7)$ & $6(5.8)$ & $13(12.5)$ \\
Between the innominate and left carotid arteries & $6(5.8)$ & $1(0.96)$ & $7(6.7)$ \\
Left carotid artery & $3(2.9)$ & $1(0.96)$ & $4(3.8)$ \\
Between the left carotid and subclavian arteries & $12(11.5)$ & $8(7.7)$ & $20(19.2)$ \\
Left subclavian artery & $8(7.7)$ & $11(10.6)$ & $19(18.3)$ \\
Not described & $19(18.3)$ & $22(21.2)$ & $41(39.4)$ \\
\hline
\end{tabular}

Data are $\mathrm{n}(\%)$.

\section{Operative Mortality and Morbidity}

Operative mortality in the arch group was $8.6 \%$ ( 9 of $104)$, not significantly different from the non-arch group $(6.0 \%, 44$ of 728$)(P=.308)$. The cause of death was multiorgan failure in 4 cases $(3.8 \%)$, low cardiac output in 3 cases $(2.9 \%)$, stroke in 1 case $(1.0 \%)$, and mediastinal infection in 1 case $(1.0 \%)$ (Table 4$)$.

Tables 4 and 5 list the outcomes of 19 early morbidities occurring in 17 patients $(16.3 \%)$. Stroke occurred in 2 patients $(1.9 \%) ; 1$ of these patients died at 26 days $(1.0 \%)$, and the other recovered. Spinal cord injury occurred in 3 cases $(2.9 \%)$, all manifesting as paraplegia; 1 patient died of multiorgan failure at 50 days during the initial hospitalization, and the other 2 patients survived. Acute renal failure occurred in 4 patients $(3.8 \%)$; among these, 1 patient died of multiorgan failure at 3 days, 1 patient died of stroke at 26 days, and 2 patients recovered $(1.9 \%)$. Low cardiac output occurred in 3 cases $(2.9 \%)$ and was associated with $100 \%$ mortality (3 of 3 ). Lower limb ischemia occurred in 2 cases $(1.9 \%) ; 1$ patient died of multiorgan failure at 8 days, and the other recovered after medical management. Recurrent laryngeal nerve injury occurred in 1 case $(1.0 \%)$. Reexploration for bleeding was required in 2 patients $(1.9 \%), 1$ of whom died of multiorgan failure at 2 days. Pericardial drainage for effusion was required in 1 case $(1.0 \%)$.

\section{Long-Term Outcomes}

Long-term follow-up (mean duration, $5.6 \pm 2.6$ years) was complete in $100 \%$ (95 of 95) and extended to 12 years (range, 1.3-11.6 years). Late death occurred in 2 cases $(1.9 \%)$. The first occurred in the only patient with Marfan syndrome of the arch group, who died of recurring dissection in the distal descending aorta at 2.8 years. A second patient died of pneumonia at 1.3 years. Survival was $89.2 \%$ at 5 and 8 years (95\% CI, 81.3\%-93.9\%) (Figure 2).

At the latest follow-up, 93 of 95 patients $(96.8 \%)$ were alive, and no new cases of stroke or spinal cord injury had occurred. Late adverse events occurred in 3 cases. At 3 months, endoleak was detected at the anastomosis between the open stent graft and the 4-branched arch graft into the false lumen in an asymptomatic patient, which resolved at 1.5 years. One patient underwent coronary artery stenting because of coronary artery disease at 1 year, and another patient sustained a malignant arrhythmia, which necessitated implantation of a cardioverter defibrillator at 2 years. One patient who sustained paraplegia postoperatively was still confined to bed at 2.5 years. No secondary

TABLE 3. Operative data

\begin{tabular}{|c|c|c|c|c|}
\hline Variable & $\begin{array}{c}\text { Total } \\
(\mathbf{n}=\mathbf{8 3 2})\end{array}$ & $\begin{array}{c}\text { Arch group } \\
(\mathbf{n}=104)\end{array}$ & $\begin{array}{l}\text { Non-arch group } \\
\quad(\mathbf{n}=\mathbf{7 2 8})\end{array}$ & $P$ value \\
\hline \multicolumn{5}{|l|}{ Procedural times, min, mean $\pm \mathrm{SD}$} \\
\hline Cardiopulmonary bypass time & $193 \pm 51$ & $196 \pm 47$ & $193 \pm 52$ & .515 \\
\hline Cross-clamp time & $106 \pm 40$ & $114 \pm 78$ & $105 \pm 32$ & .235 \\
\hline Unilateral perfusion time & $25 \pm 9$ & $28 \pm 11$ & $24 \pm 8$ & $.007 *$ \\
\hline Aortic valve or root procedures, $\mathrm{n}(\%)$ & $408(49.0)$ & $41(39.4)$ & $367(50.4)$ & .036 \\
\hline Aortic valve resuspension & $102(12.3)$ & $24(23.1)$ & $78(10.7)$ & $<.001$ \\
\hline Sinus of Valsalva repair & $25(3.0)$ & $6(5.8)$ & $19(2.6)$ & .114 \\
\hline Aortic valve replacement & $10(1.2)$ & $1(1.0)$ & $9(1.2)$ & .999 \\
\hline Bentall procedure & $256(30.8)$ & $10(9.6)$ & $246(33.8)$ & $<.001$ \\
\hline Other (David, Cabrol, and Wheat) & $15(1.8)$ & $0(0)$ & $15(2.0)$ & .238 \\
\hline Concomitant procedures, $\mathrm{n}(\%) \dagger$ & $112(13.5)$ & $10(9.6)$ & $102(14.0)$ & .292 \\
\hline Coronary artery bypass grafting & $69(8.3)$ & $10(9.6)$ & $59(8.1)$ & .601 \\
\hline Extra-anatomic bypass & $28(3.4)$ & $0(0)$ & $28(3.8)$ & .039 \\
\hline Mitral valve operation & $15(1.8)$ & $0(0)$ & $15(2.1)$ & .238 \\
\hline
\end{tabular}

Unilateral cerebral perfusion time refers to the interval from initiation of hypothermic circulatory arrest to completion of left carotid anastomosis, after which the brain is perfused bilaterally. Unilateral cerebral perfusion time is longer than the time of hypothermic circulatory arrest, when lower body perfusion is stopped to implant the open stent graft and suture the distal anastomosis. $S D$, Standard deviation. *Mann-Whitney $U$ test. $\nmid$ Refers to the number of patients in whom concomitant procedures were performed. Specific procedures are expressed as number of cases. 
TABLE 4. Operative mortality and morbidity

\begin{tabular}{lcccc}
\hline \multicolumn{1}{c}{ Variable } & $\begin{array}{c}\text { Total } \\
(\mathbf{n}=\mathbf{8 3 2})\end{array}$ & $\begin{array}{c}\text { Arch } \\
\text { group } \\
(\mathbf{n}=\mathbf{1 0 4})\end{array}$ & $\begin{array}{c}\text { Non-arch } \\
\text { group } \\
(\mathbf{n}=\mathbf{7 2 8})\end{array}$ & $\begin{array}{c}\boldsymbol{P} \\
\text { value }\end{array}$ \\
\hline Mortality & $53(6.4)$ & $9(8.7)$ & $44(6.0)$ & .308 \\
$\quad$ Multiorgan failure & $25(3.0)$ & $4(3.8)$ & $21(2.9)$ & .540 \\
Stroke & $10(1.2)$ & $1(1.0)$ & $9(1.2)$ & .999 \\
Low cardiac output & $10(1.2)$ & $3(2.9)$ & $7(1.0)$ & .118 \\
Mediastinal infection & $1(0.1)$ & $1(1.0)$ & $0(0)$ & .125 \\
Other & $7(0.1)$ & $0(0)$ & $7(0.9)$ & .667 \\
Morbidity & & & & \\
Stroke & $17(2.0)$ & $2(1.9)$ & $15(2.1)$ & .999 \\
Spinal cord injury & $20(2.4)$ & $3(2.9)$ & $17(2.3)$ & .729 \\
Renal failure & $28(3.4)$ & $4(3.8)$ & $24(3.3)$ & .770 \\
Low cardiac output & $13(1.6)$ & $3(2.9)$ & $10(1.4)$ & .215 \\
Lower extremity ischemia & $7(0.8)$ & $2(1.9)$ & $5(0.7)$ & .473 \\
Recurrent laryngeal nerve & $9(1.1)$ & $1(1.0)$ & $8(1.1)$ & .999 \\
$\quad$ injury & & & & \\
Reinterventions & $41(4.9)$ & $3(2.9)$ & $38(5.2)$ & .303 \\
Reexploration for bleeding & $28(3.4)$ & $2(1.9)$ & $26(3.6)$ & .563 \\
Pericardial drainage for & $7(0.8)$ & $1(1.0)$ & $6(0.8)$ & .999 \\
$\quad$ effusion & & & & \\
Other & $6(0.7)$ & $0(0)$ & $6(0.8)$ & .757 \\
\hline Data are n (\%). & & & &
\end{tabular}

intervention on the distal aorta was required. Freedom from late adverse events was $85.0 \%$ (95\% CI, $76.3 \%-90.8 \%)$ at 5 and 8 years (Figure 3 ).

\section{Late Radiologic Follow-up}

Follow-up CT scan was available in 65 patients at a mean of $4.6 \pm 2.9$ years postoperatively (range, 1.3-11.2 years). Incomplete obliteration of the false lumen at the distal end of the FET was seen in 2 patients at 1 year, but longer follow-up CT was unavailable in these 2 patients. Endoleak occurred at the distal anastomosis into the false lumen in 1 patient, and resolved at 1.5 years. At the level of the distal end of the open stented graft, the false lumen was completely obliterated in 63 of the 65 CT scans (Figure 4) performed at a mean of $4.6 \pm 2.9$ years postoperatively. Linear mixed model estimates revealed that in both the stented and unstented distal aortic segments, the maximum diameters of the false lumen and aorta decreased over time $(P<.001)$, whereas the maximum diameter of the true lumen showed a significant increase $(P<.001)$. These model estimates also indicated that each of these temporal trends was more pronounced in the stented aortic segment than in the unstented distal aortic segment $(P<.001)$, as depicted in Figure 5. The average aortic size, measuring the largest part of the distal aorta, was $25.7 \pm 5.3 \mathrm{~mm}$ at 1 year, $24.1 \pm 1.9 \mathrm{~mm}$ at 3 years, $21.3 \pm 2.7 \mathrm{~mm}$ at 5 years, and $25.4 \pm 0.2 \mathrm{~mm}$ at 8 years.

\section{Risk Factors for Arch Entry Tear and Early Outcomes}

Univariate analysis identified hypertension as associated with arch entry tear (odds ratio [OR], 2.589; 95\% CI, $1.486-4.510 ; P<.001)$. In multivariate analysis, risk factors for arch entry tear were age in years (OR, $1.025 ; 95 \% \mathrm{CI}$ 1.002-1.048; $P=.032$ ) and hypertension (OR, 2.091; 95\% CI, 1.186-3.687; $P=.011)$. Patients with Marfan syndrome were less likely than those without Marfan syndrome to develop an arch entry tear (OR, 0.131; 95\% CI, 0.017-0.979; $P=.048$ ).

TABLE 5. Outcomes of operative morbidities

\begin{tabular}{|c|c|c|c|c|c|}
\hline Patient & Comorbidity or malperfusion & $\begin{array}{c}\text { Days from } \\
\text { onset }\end{array}$ & CPB time, min & Early morbidity & Outcome/cause and time of death \\
\hline 1 & None & 4.9 & 156 & Low cardiac output & Death/low cardiac output, $6 \mathrm{~h}$ \\
\hline 2 & $\begin{array}{c}\text { Coronary artery disease; } \\
\text { cerebral malperfusion }\end{array}$ & 1.2 & 406 & Low cardiac output & Death/low cardiac output, $48 \mathrm{~h}$ \\
\hline 3 & Cerebrovascular disease & 0.5 & 164 & Low cardiac output & Death/low cardiac output, $5 \mathrm{~h}$ \\
\hline 4 & None & 2.2 & 160 & Spinal cord injury & Death/multiorgan failure, $50 \mathrm{~d}$ \\
\hline 5 & None & 1.8 & 163 & Acute renal failure & Death/multiorgan failure, $36 \mathrm{~h}$ \\
\hline 6 & Coronary malperfusion & 0.6 & 288 & Lower extremity ischemia & Death/multiorgan failure, $8 \mathrm{~d}$ \\
\hline 7 & None & 2.3 & 182 & Bleeding & Death/multiorgan failure, $48 \mathrm{~h}$ \\
\hline 8 & None & 6.0 & 320 & Stroke; acute renal failure & Death/stroke, $26 \mathrm{~d}$ \\
\hline 9 & None & 5.0 & 264 & Mediastinal infection & Death/mediastinal infection, $26 \mathrm{~d}$ \\
\hline 10 & None & 3.1 & 217 & $\begin{array}{l}\text { Spinal cord injury; recurrent } \\
\text { laryngeal nerve injury }\end{array}$ & Survival \\
\hline 11 & Cerebrovascular disease & 1.6 & 226 & Spinal cord injury & Survival \\
\hline 12 & None & 0.8 & 293 & Stroke & Survival \\
\hline 13 & None & 6.0 & 173 & Acute renal failure & Survival \\
\hline 14 & None & 1.1 & 192 & Acute renal failure & Survival \\
\hline 15 & None & 1.4 & 200 & Lower extremity ischemia & Survival \\
\hline 16 & Renal malperfusion & 3.4 & 177 & Bleeding & Survival \\
\hline 17 & None & 2.6 & 216 & Pericardial effusion & Survival \\
\hline
\end{tabular}

$C P B$, Cardiopulmonary bypass. 


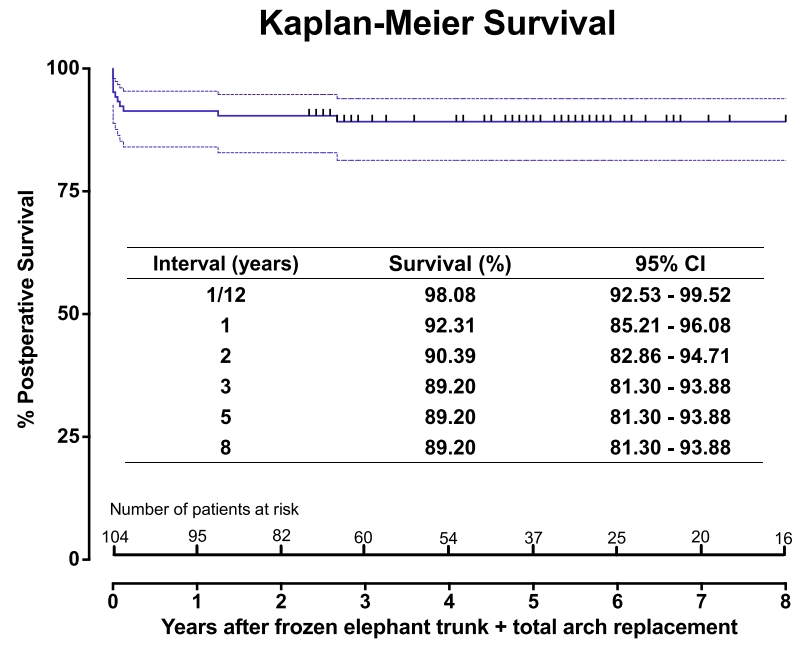

FIGURE 2. Survival of patients with arch dissections after FET + TAR. $C I$, Confidence interval.

In the arch group, the CPB time was significantly longer in patients with early mortality and morbidity than in those without early mortality and morbidity (mean, $223 \pm 69$ minutes [range, 156-406 minutes] vs $191 \pm 39$ minutes [range, 117-340 minutes]; $P=.008$ ). When a composite endpoint was selected, CPB time (in minutes) was identified as a risk factor increasing the composite outcome (OR, 1.013; 95\% CI, 1.001-1.024; $P=.008$ ), whereas patients who underwent repair at a longer interval from symptom onset showed a significant trend toward decreased operative mortality and morbidity (OR, 0.712; 95\% CI, 0.545-0.929; $P=.019$ ) (Table 6).

\section{DISCUSSION}

Aortic dissection with arch entry tear is a complicated subgroup of aortic dissections. ${ }^{22}$ The proportion of arch

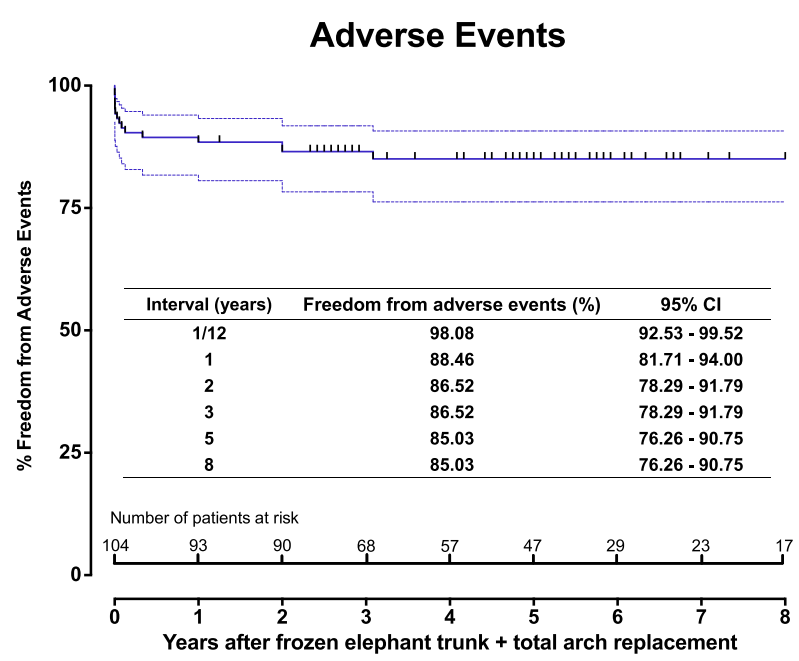

FIGURE 3. Freedom from adverse events in patients with arch dissections following FET + TAR, including endoleak, coronary artery disease, and malignant arrhythmia. $C I$, Confidence interval. dissections varies in different reports, ranging from $9 \%$ to $31 \%$ of TAADs, ${ }^{3,4}$ and operative mortality in early series of acute arch dissections has ranged from $29 \%$ to $35 \%$. ${ }^{6,9}$ Although the surgical outcomes for aortic arch dissections have improved considerably over the past 2 decades, the operative mortality remains as high as $23.1 \%$ in contemporary series. ${ }^{25}$ There is ongoing debate regarding the optimal approach for surgical repair, especially regarding the extent of distal repair. To date, few series have reported the long-term surgical outcome in this specific group of patients..$^{14,17,32}$ Despite the fact that the FET technique has been gaining wider use, ${ }^{23}$ its indications and safety remain under debate, and data on long-term outcomes are insufficient. ${ }^{23-25,27,28}$ In this study, we evaluated the efficacy of the FET technique for acute arch dissections by analyzing early and late outcomes in a group of 104 patients over a 12-year period.

This group of 104 patients represented $12.5 \%$ of the 832 patients with TAAD who underwent FET + TAR (ie, the Sun procedure) at our center. This proportion is lower than that in most reported clinical series of arch dissections. ${ }^{14,16,20,22,32}$ Although in this series, these patients' operative mortality of $8.6 \%$ was higher than the $6.0 \%$ in patients with TAAD with an entry tear located elsewhere $(6.0 \%)$, it is still comparable to that of most series (Table 7). ${ }^{6-23,25,32}$ The rates of stroke, spinal cord injury, and other early morbidities were also consistently low in this study. While Uchida and colleagues ${ }^{27}$ and Shimamura and colleagues ${ }^{28}$ reported lower early mortality rates in patients with acute TAAD $(4.5 \%$ and $6.5 \%$, respectively), the locations of entry tears were not disclosed. Late survival and freedom from adverse events were $89.2 \%$ and $85.0 \%$ at 5 and 8 years, respectively, and no reintervention was required on the distal aorta.

Longitudinal analysis of follow-up CT scans has shown that the FET technique promotes long-term remodeling of the dissected aorta, as evidenced by the significant temporal trend toward false lumen shrinkage and true lumen expansion in both the stented and unstented aortic segments. The remodeling effect was more pronounced across the stented aortic segment, with false lumen obliteration at the distal end of the FET in 63 of 65 patients. These long-term outcomes compare favorably to those reported in most contemporary studies of the FET technique. ${ }^{23,25-28}$ The satisfactory early and late outcomes demonstrate the safety and efficacy of the Sun procedure in patients with TAAD with an arch entry tear. These results add favorable evidence in support of the wider application of the FET technique as a safe and effective approach to treating TAAD.

The reasons for such favorable clinical outcomes are manifold. The Cronus stented graft used in the Sun procedure plays a pivotal role owing to its innovative design 

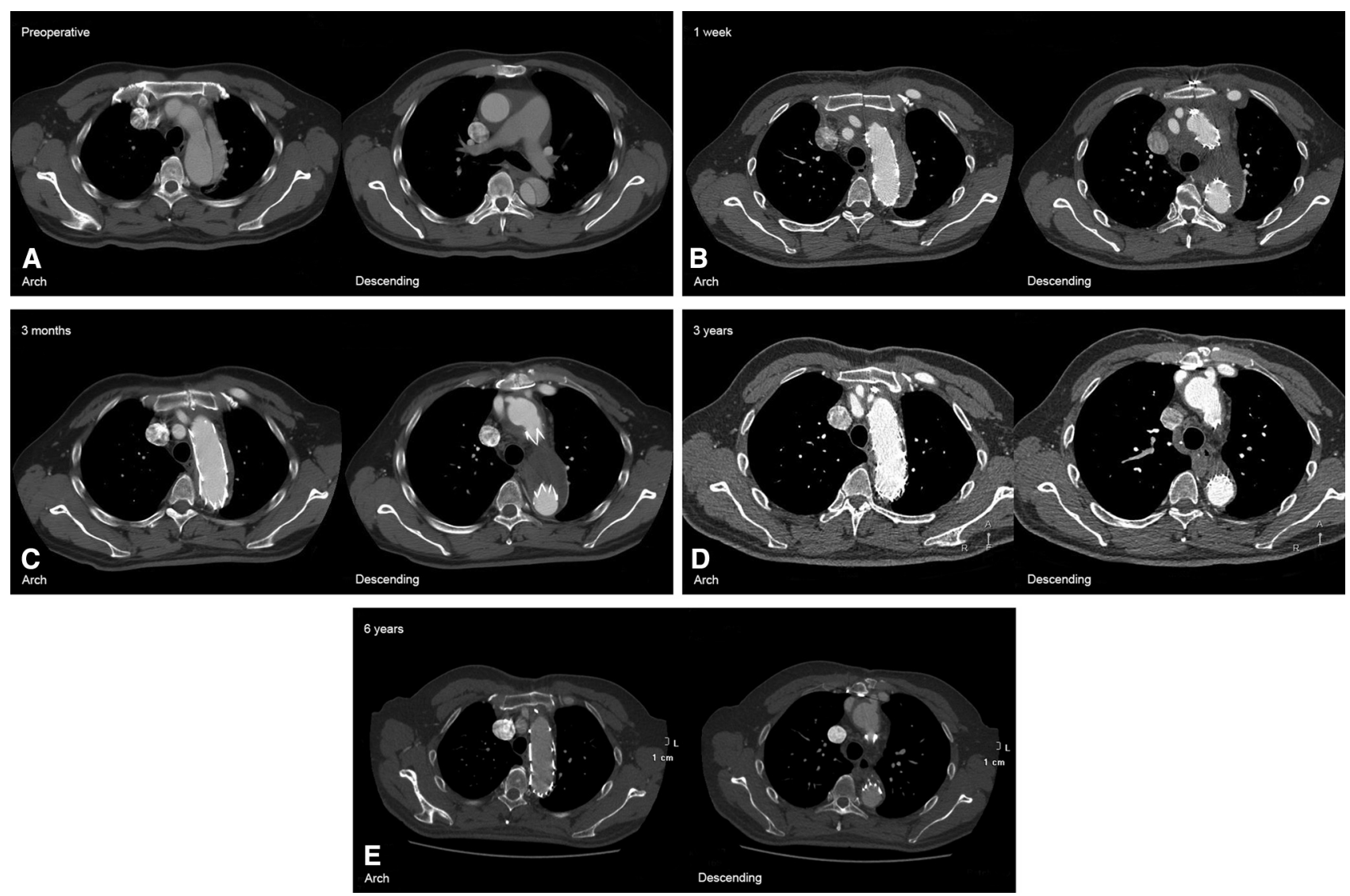

FIGURE 4. Preoperative and follow-up CT scans in a 38-year-old man who presented with substernal pain for 2 days. He was diagnosed with acute TAAD with an arch entry tear and underwent emergent surgical repair with FET + TAR. A, Preoperative CT scan. B, CT scan at discharge (1 week). C, CT scan at 3 months. D, Follow-up CT scan at 3 years. E, Follow-up CT scan at 6 years.

and technical simplicity of implantation. ${ }^{29,33}$ This graft can be implanted very quickly and easily, thus decreasing the circulatory arrest time. The interplay of surgical techniques and organ protection strategies is also synergistic and contributory. On completion of the distal anastomosis, distal reperfusion is started. We also apply a special sequence for aortic reconstruction that prioritizes for resumption of blood supply to the brain and myocardium, minimizing the duration of spinal cord, cerebral, and myocardial ischemia. Albeit simple, these time-tested strategies are effective approaches to spinal cord and cerebral protection, ${ }^{34}$ as evidenced by the low incidence of stroke and paraplegia in this series.

This aggressive strategy flies in the face of the commonly held premise that a more conservative surgical approach is generally warranted owing to the emergent nature of these cases and the friability of aortic tissues. Other groups have also achieved favorable results in patients with TAAD using either a hemiarch or isolated TAR. ${ }^{24,35}$ Even without an FET, patients with a hemiarch or total arch repair would probably have done as well; however, our experience has shown that this extensive procedure is likely to benefit patients in the long run. Use of an FET helps promote false lumen obliteration and minimize the need for reinterventions on the distal aorta in the long term, and also reduces the risk of bleeding at the distal anastomosis. Uchida and colleagues ${ }^{26}$ reported a series of 120 patients with acute TAAD undergoing FET + TAR. The 10-year survival was $75 \%$, and the overall 10 -year freedom from reoperation on the thoracic aorta was $93 \%$. In a recent study of 803 patients with TAAD, we found that operative mortality after FET + TAR was not different for acute and chronic aortic dissections, but instead it was primarily the preoperative malperfusion syndrome (of the brain, myocardium, viscera, and spinal cord) that affected operative mortality. ${ }^{29}$ Although the difference between an acute, unstable patient with TAAD presenting for emergent surgery in the middle of the night and a patient presenting several days from the acute event self-selected by surviving the first 48-72 hours in stable condition cannot be overemphasized, the results of our previous study ${ }^{29}$ imply that this extensive procedure can be safely performed in the acute, stable patients without increasing the risk of early mortality or morbidity. In our early experience, we achieved 
Stented

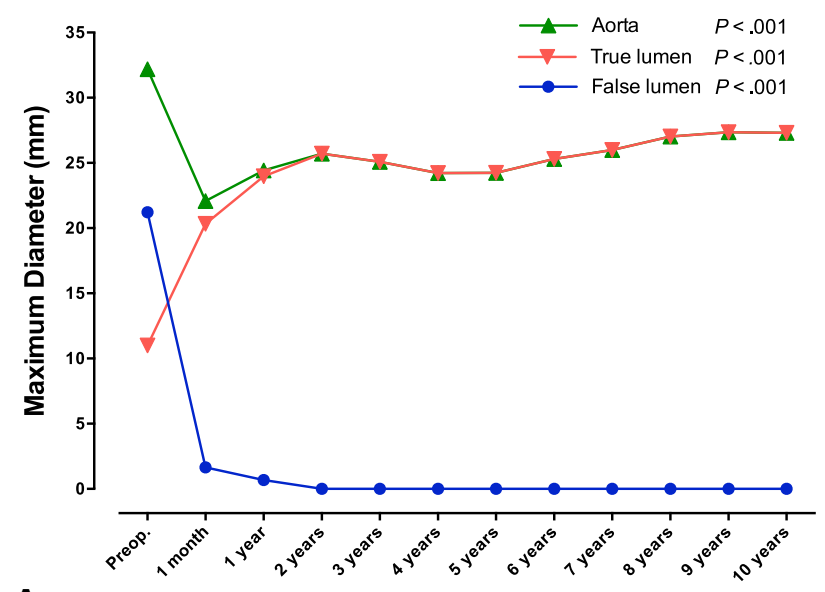

A Time after frozen elephant trunk + total arch replacement

\section{True Lumen}

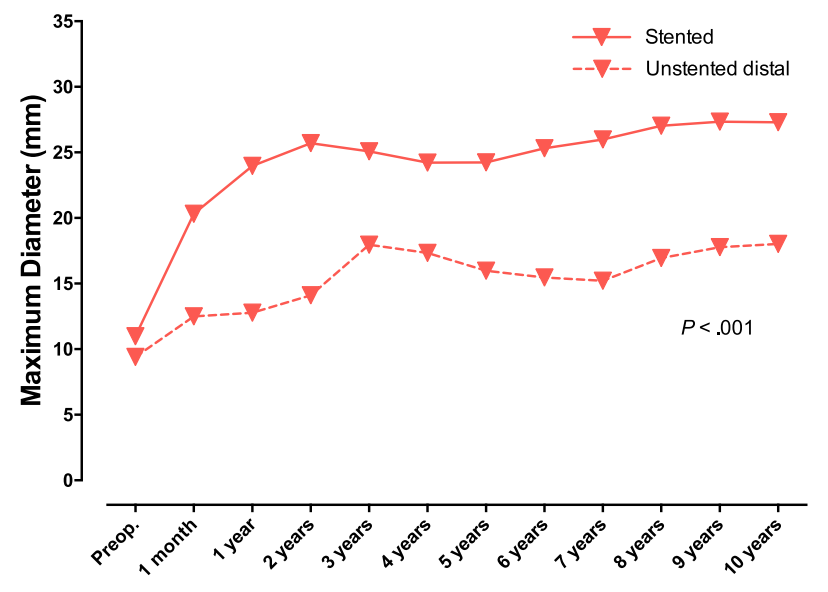

C Time after frozen elephant trunk + total arch replacement

\section{Unstented Distal}

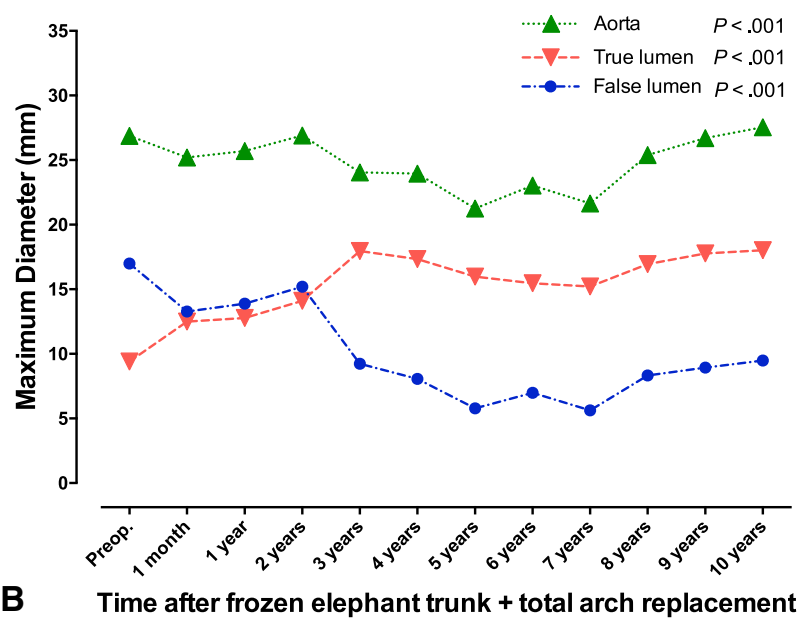

False Lumen and Aorta

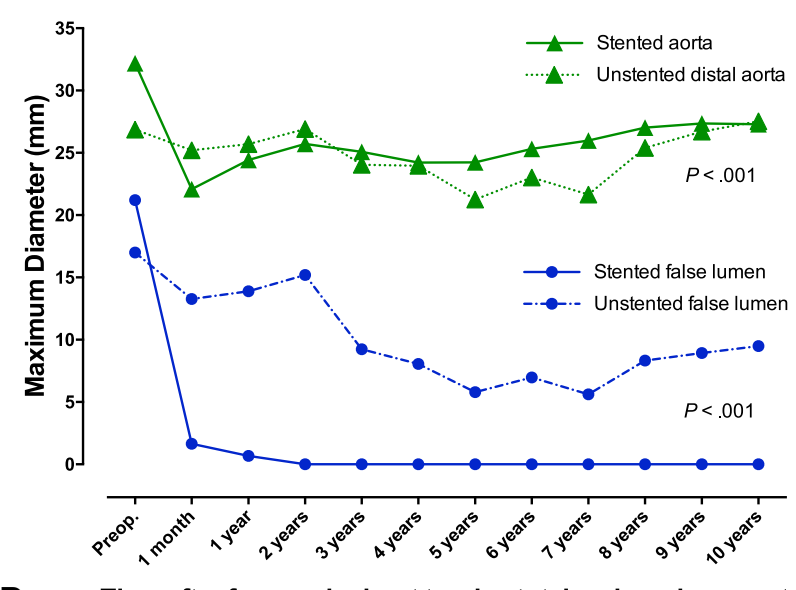

D Time after frozen elephant trunk + total arch replacement

FIGURE 5. Following FET + TAR, both the stented (A) and unstented distal (B) segments showed significant temporal trends toward false lumen shrinkage and true lumen expansion. These trends in the diameter changes of the true lumen (C) and the false lumen and aorta (D) were more evident across the stented segment. The unstented true and false lumens are indicated by dashed lines; the unstented aortic segment, by a dotted line.

a mortality of $4.7 \%$ with FET + TAR in 148 patients with acute TAAD, which compares favorably with the $6.1 \%$ reported in a similar group of 66 patients undergoing hemiarch repair. At a mean follow-up of more than 42 months, survival was similar in both groups, but the FET + TAR group had a significantly higher rate of false lumen thrombosis $(94.2 \%$ vs $14.5 \%, P<.001)$ and required fewer surgical reinterventions $(0.7 \%$ vs $6.5 \%, P=.031) .{ }^{36}$ In particular, owing to differences in culture, costs, and approaches to health care in China, the majority of our patients are extremely unwilling and unlikely to return for a second-stage operation on the downstream aorta. Under such special circumstances, we believe that any intervention on the descending aorta during the primary operation is beneficial to patients in the long term.
Paraplegia has plagued many series of FET procedures. ${ }^{23}$ Although the FET procedure may put this group of patients at added risk, we speculate that the occurrence of postoperative paraplegia in patients with TAAD might not be related to the procedure. Aortic dissection itself may cause paraplegia. In the German Registry for Acute Aortic Dissection Type A, 5.5\% of patients (26 of 658) sustained paraplegia preoperatively. ${ }^{37}$ We hypothesize that in cases where important intercostal arteries are supplied by the false lumen, paraplegia may occur when the false lumen closes spontaneously or is obliterated by an FET. The difficulties of eliminating spinal cord injury relates to various factors, including hemodynamic status, technical aspects, adjuncts, neuromonitoring, pharmacologic agents, and intraoperative and postoperative complications. Our 
TABLE 6. Risk factors for arch entry tear and early outcomes

\begin{tabular}{|c|c|c|c|}
\hline Risk factor & OR & $95 \% \mathrm{CI}$ & $P$ value \\
\hline \multicolumn{4}{|c|}{ Arch entry tear (in all 832 type A dissections)* } \\
\hline Age (y) & 1.025 & $1.002-1.048$ & .032 \\
\hline Hypertension & 2.091 & $1.186-3.687$ & .011 \\
\hline Marfan syndrome & 0.131 & $0.017-0.979$ & .048 \\
\hline \multicolumn{4}{|c|}{ Early mortality and morbidity (in arch dissections) $\dagger$} \\
\hline Cardiopulmonary bypass time (min) & 1.013 & $1.001-1.024$ & .008 \\
\hline Time from onset to surgery (d) & 0.712 & $0.545-0.929$ & .019 \\
\hline \multicolumn{4}{|c|}{$\begin{array}{l}O R \text {, Odds ratio; } C I \text {, confidence interval. *Variables considered in the analysis } \\
\text { included age, gender, acuity, hypertension, Marfan syndrome, diabetes mellitus, } \\
\text { coronary artery disease, cerebral vascular disease, and chronic kidney disease. } \\
\dagger \text { Variables considered in the analysis included age, gender, times from onset to } \\
\text { surgery, hypertension, coronary artery disease, cerebrovascular disease, chronic } \\
\text { kidney disease, malperfusion syndrome, acute heart failure, acute cardiac tamponade, } \\
\text { aortic valve or root procedures, aortic valve resuspension, Bentall procedure, } \\
\text { concomitant procedure, coronary artery bypass grafting, extra-anatomic bypass, car- } \\
\text { diopulmonary bypass time, cross-clamp time, and selective cerebral perfusion time. }\end{array}$} \\
\hline
\end{tabular}

strategies for minimizing this risk are rather simple, including (1) a relatively short stent graft, averaging $10 \mathrm{~cm}$ in length and implanted above T6 in most cases; (2) a distal-first strategy, to minimize the duration of spinal cord ischemia; and (3) cerebrospinal fluid drainage and neuromonitoring in high-risk patients. With these measures, we were able to keep the incidence of spinal cord injury at $2.4 \%$ in this series, a rate comparable or even superior to those of most contemporary series. ${ }^{23,26-28}$

This study reveals several clinical and pathological features of aortic dissections with arch entry tear. Compared with patients with entry tears located elsewhere, those with arch dissection were somewhat older, and presented and underwent surgical repair exclusively in the acute phase. Hypertension was predominant, seen in $84.6 \%$ of patients, and carried a twofold increased risk for developing dissection with an arch entry tear. The high incidence of hypertension in this series not only accounts, to a greater degree, for the extremely young age of our patients (average, 46 years), but also reflects the huge burden of cardiovascular disease in China.

Despite their genetic susceptibility to aortic dissection, patients with Marfan syndrome were less likely than those without Marfan syndrome to develop an arch entry tear, which is explained by the typical dilatation of the sinuses of Valsalva and aortic root in patients with Marfan syndrome. The changes in the aortic root of Marfan patients increase the risk of dissection of the aortic root and ascending aorta, but save the aortic arch from developing an intimal tear.

Owing to location, arch dissections involve the transverse arch and arch branches more frequently and severely than the aortic root. This led to the significantly higher rate of aortic valve resuspension and lower rate of composite graft root replacement, without the need for extra-anatomic bypass in the arch group compared with the non-arch group.

This retrospective study has several limitations, as have been described previously. ${ }^{29}$ Most important is the strikingly young average age of the patients in our series. The main reasons for this are both genetic and environmental. There may be some genetic factors that

TABLE 7. Published reports on aortic arch dissections: frequency and surgical outcomes

\begin{tabular}{|c|c|c|c|c|c|c|}
\hline Report & Year & Years of study & No. of patients & $\begin{array}{c}\text { Arch entry tear in } \\
\text { type A dissections, n (\%) }\end{array}$ & Operative mortality, $\%$ & 5-y survival, $\%$ \\
\hline Miller et $\mathrm{al}^{6}$ & 1979 & 16 & 125 & $18(14.4)$ & $29 *$ & $54 *$ \\
\hline Livesay et $\mathrm{al}^{7}$ & 1982 & 1 & 15 & $10(67)$ & 7 & NA \\
\hline Haverich et $\mathrm{al}^{8}$ & 1985 & 18 & 135 & $9(6.7)$ & NA & $79 *$ \\
\hline 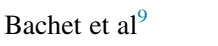 & 1988 & 17 & 119 & $26(21.8)$ & 34.6 & NA \\
\hline Lansman et $\mathrm{al}^{22}$ & 1989 & 9 & 19 & $19(100)$ & 21.0 & 74 \\
\hline Heinemann et $\mathrm{al}^{12}$ & 1991 & 11 & 106 & $19(17.9)$ & $20.6 *$ & NA \\
\hline Yun et $\mathrm{al}^{11}$ & 1991 & 20 & 53 & $26(49.1)$ & 28 & 71 \\
\hline Tabayashi et $\mathrm{al}^{13}$ & 1993 & 6 & 20 & $20(100)$ & 15 & NA \\
\hline Suda et $\mathrm{al}^{15}$ & 1996 & 10 & 24 & $24(100)$ & 36.4 & NA \\
\hline Okita et $\mathrm{al}^{14}$ & 1996 & 18 & 325 & $72(22.2)$ & 9.7 & 85.3 \\
\hline 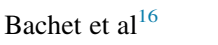 & 1999 & 21 & 204 & $58(28.4)$ & 25 & 79.7 \\
\hline 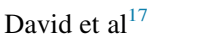 & 1999 & 18 & 109 & $16(14.6)$ & 15.0 & 56.0 \\
\hline Lansman et $\mathrm{al}^{22}$ & 1999 & 12 & 139 & $32(23.0)$ & 18.8 & 74 \\
\hline Kazui et al $^{32}$ & 2000 & 10 & 118 & $28(23.7)$ & $15.4 *$ & $77 *$ \\
\hline Hirotani et al ${ }^{19}$ & 2000 & 4 & 27 & $5(18.5)$ & $11 *$ & $85 *$ \\
\hline Apaydin et $\mathrm{al}^{20}$ & 2003 & 6 & 108 & $16(14.8)$ & 18.7 & NA \\
\hline Kirali et $\mathrm{al}^{21}$ & 2004 & 8 & 42 & 5 (11.9) & $28.6 *$ & $62.3^{*}$ \\
\hline Shimamura et $\mathrm{al}^{28}$ & 2008 & 10 & 126 & NA & $5.5^{*}$ & $63.3^{*}$ \\
\hline 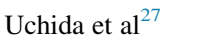 & 2010 & 11 & 156 & NA & $4.5 *$ & $86.5^{*}$ \\
\hline Di Eusanio et al $^{25}$ & 2014 & 16 & 623 & NA & $15.1^{*}$ & $79.4^{*}$ \\
\hline Ma et al & 2015 & 12 & 832 & $104(12.5)$ & 8.6 & 89.2 \\
\hline
\end{tabular}

NA, Not available. *Including data on type A dissections with entry tears located both in the arch and elsewhere. 
predispose the Chinese population to develop aortic dissection at a young age, which have not been extensively investigated to date. Because the level of healthcare is not as high as in Western countries and due to the rapid socioenvironmental changes in China, many patients with cardiovascular disease do not receive proper care and monitoring. This has led to an extremely high prevalence of hypertension in the Chinese population. According to a recent survey ${ }^{38}$ the adjusted prevalence of hypertension in China is $29.6 \%$, which corresponds to 325 million individuals. Rates of awareness, treatment, and control in participants were $42.6 \%, 34.1 \%$ and $9.3 \%$, respectively. The control percentage among all treated participants was as low as $27.4 \%$. These low percentages of awareness, treatment, and control of hypertension contributed a great deal to the predominance of young patients in our series.

Other concerns pertain to delays in surgery and patient selection. The average interval from onset to surgery in the arch group was nearly 5 days. The main reason for this was that more than $80 \%$ of our patients had been diagnosed at a remote or peripheral hospital and transferred to our institution, a major aortic referral center in China, which in many cases is a long distance away. As a result of this natural selection, we were operating on a subset of lower-risk patients and survivors of the early hazard phase of aortic dissection (the first 48 hours). Our center is also constrained by the paucity of qualified surgical personnel and advanced medical facilities, which exacerbates this situation. For patients with the surgical indications but with malperfusion syndrome, our policy is to operate, as long as no end-organ failure has occurred. However, in the most severe cases with shock or morbid types of malperfusion, we are very selective and cautious in performing any type of surgical repair (limited or extended), owing to the guarded prognosis in this subset of patients.

\section{CONCLUSIONS}

In this study, surgical repair of TAAD with arch entry tear using the FET + TAR technique was not associated with increased operative mortality and morbidity compared with repair of other TAADs, and achieved satisfactory early and late survival rates and freedom from late reinterventions and adverse events. These results argue favorably for use of the more extensive FET + TAR approach in the management of TAADs with arch entry tear.

\section{Conflict of Interest Statement}

Dr Elefteriades reports consulting fees from Jarvik Heart and equity ownership in CoolSpine. All other authors have nothing to disclose with regard to commercial support.
You can watch a Webcast of this AATS meeting presentation by going to: http://webcast.aats.org/2015/Video/Tuesday/ 04-28-15_612_1603_Ma.mp4.

\section{References}

1. DeBakey ME, Henly WS, Cooley DA, Morris GC Jr, Crawford ES, Beall AC Jr. Surgical management of dissecting aneurysms of the aorta. J Thorac Cardiovasc Surg. 1965;49:130-49.

2. Daily PO, Trueblood HW, Stinson EB, Wuerflein RD, Shumway NE. Management of acute aortic dissections. Ann Thorac Surg. 1970;10:237-47.

3. Hirst AE Jr, Johns VJ Jr, Kime SW Jr. Dissecting aneurysm of the aorta: a review of 505 cases. Medicine (Baltimore). 1958;37:217-79.

4. Ergin MA, O'Connor J, Guinto R, Griepp RB. Experience with profound hypothermia and circulatory arrest in the treatment of aneurysms of the aortic arch: aortic arch replacement for acute arch dissections. J Thorac Cardiovasc Surg. 1982;84:649-55.

5. Lansman SL, Ergin MA, Griepp RB. Treatment of acute aortic arch dissection. Ann Thorac Surg. 1993;55:816-7.

6. Miller DC, Stinson EB, Oyer PE, Rossiter SJ, Reitz BA, Griepp RB, et al. Operative treatment of aortic dissections: experience with 125 patients over a sixteen-year period. J Thorac Cardiovasc Surg. 1979;78:365-82.

7. Livesay JJ, Cooley DA, Duncan JM, Ott DA, Walker WE, Reul GJ. Open aortic anastomosis: improved results in the treatment of aneurysms of the aortic arch. Circulation. 1982;66(2 Pt 2):I122-7.

8. Haverich A, Miller DC, Scott WC, Mitchell RS, Oyer PE, Stinson EB, et al. Acute and chronic aortic dissections: determinants of long-term outcome for operative survivors. Circulation. 1985;72:II22-34.

9. Bachet J, Teodori G, Goudot B, Diaz F, el Kerdany A, Dubois C, et al. Replacement of the transverse aortic arch during emergency operations for type A acute aortic dissection: report of 26 cases. J Thorac Cardiovasc Surg. 1988;96:878-86.

10. Lansman SL, Raissi S, Ergin MA, Griepp RB. Urgent operation for acute transverse aortic arch dissection. J Thorac Cardiovasc Surg. 1989;97: 334-41.

11. Yun KL, Glower DD, Miller DC, Fann JI, Mitchell RS, White WD, et al. Aortic dissection resulting from tear of transverse arch: is concomitant arch repair warranted? J Thorac Cardiovasc Surg. 1991;102:355-68.

12. Heinemann M, Laas J, Jurmann M, Karck M, Borst HG. Surgery extended into the aortic arch in acute type A dissection: indications, techniques, and results. Circulation. 1991;84(5 Suppl):III25-30.

13. Tabayashi K, Niibori K, Iguchi A, Shoji Y, Ohmi M, Mohri H. Replacement of the transverse aortic arch for type A acute aortic dissection. Ann Thorac Surg. 1993;55:864-7.

14. Okita Y, Takamoto S, Ando M, Morota T, Yamaki F, Kawashima Y, et al. Surgery for aortic dissection with intimal tear in the transverse aortic arch. Eur J Cardiothorac Surg. 1996;10:784-90.

15. Suda H, Itoh T, Natsuaki M, Minato N, Ueno T, Ohteki H. Surgical treatment for acute aortic arch dissection. Cardiovasc Surg. 1996;4:315-9.

16. Bachet J, Goudot B, Dreyfus GD, Brodaty D, Dubois C, Delentdecker P, et al. Surgery for acute type A aortic dissection: the Hopital Foch experience (1977-1998). Ann Thorac Surg. 1999;67:2006-9.

17. David TE, Armstrong S, Ivanov J, Barnard S. Surgery for acute type A aortic dissection. Ann Thorac Surg. 1999;67:1999-2001.

18. Kieffer E, Koskas F, Godet G, Bertrand M, Bahnini A, Benhamou AC, et al. Treatment of aortic arch dissection using the elephant trunk technique. Ann Vasc Surg. 2000;14:612-9.

19. Hirotani T, Kameda T, Kumamoto T, Shirota S. Results of a total aortic arch replacement for an acute aortic arch dissection. J Thorac Cardiovasc Surg. 2000;120:686-91.

20. Apaydin AZ, Islamoglu F, Posacioglu H, Calkavur T, Yagdi T, Atay Y, et al. Surgical treatment of acute arch dissection. Jpn J Thorac Cardiovasc Surg. $2003 ; 51: 48-52$.

21. Kirali K, Ardal H, Erentug V, Mansuroglu D, Bozbuga NU, Yakut C. Surgical outcome of subtypes of aortic arch dissection. Asian Cardiovasc Thorac Ann. 2004; $12: 300-5$.

22. Lansman SL, McCullough JN, Nguyen KH, Spielvogel D, Klein JJ, Galla JD, et al. Subtypes of acute aortic dissection. Ann Thorac Surg. 1999;67:1975-8.

23. Shrestha M, Bachet J, Bavaria J, Carrel TP, De Paulis R, Di Bartolomeo R, et al. Current status and recommendations for use of the frozen elephant trunk 
technique: a position paper by the Vascular Domain of EACTS. Eur J Cardiothorac Surg. 2015;47:759-69.

24. Li B, Ma WG, Liu YM, Sun LZ. Is extended arch replacement justified for acute type A aortic dissection? Interact Cardiovasc Thorac Surg. 2015;20:120-6.

25. Di Eusanio M, Berretta P, Cefarelli M, Castrovinci S, Folesani G, Alfonsi J, et al. Long-term outcomes after aortic arch surgery: results of a study involving 623 patients. Eur J Cardiothorac Surg. 2015;48:483-90.

26. Katayama A, Uchida N, Katayama K, Arakawa M, Sueda T. The frozen elephant trunk technique for acute type A aortic dissection: results from 15 years of experience. Eur J Cardiothorac Surg. 2015;47:355-60.

27. Uchida N, Katayama A, Tamura K, Sutoh M, Kuraoka M, Murao N, et al. Long-term results of the frozen elephant trunk technique for extended aortic arch disease. Eur J Cardiothorac Surg. 2010;37:1338-45.

28. Shimamura K, Kuratani T, Matsumiya G, Kato M, Shirakawa Y, Takano H, et al. Long-term results of the open stent-grafting technique for extended aortic arch disease. J Thorac Cardiovasc Surg. 2008;135:1261-9.

29. Ma WG, Zheng J, Zhang W, Sun K, Ziganshin BA, Wang LF, et al. Frozen elephant trunk with total arch replacement for type A aortic dissections: does acuity affect operative mortality? J Thorac Cardiovasc Surg. 2014;148:963-72.

30. Ma WG, Zhu JM, Zheng J, Liu YM, Ziganshin BA, Elefteriades JA, et al. Sun's procedure for complex aortic arch repair: total arch replacement using a tetrafurcate graft with stented elephant trunk implantation. Ann Cardiothorac Surg. 2013;2:642-8.

31. Sun L, Qi R, Zhu J, Liu Y, Chang Q, Zheng J. Repair of acute type A dissection: our experiences and results. Ann Thorac Surg. 2011;91:1147-52.

32. Kazui T, Washiyama N, Muhammad BA, Terada H, Yamashita K, Takinami M, et al. Extended total arch replacement for acute type A aortic dissection: experience with seventy patients. J Thorac Cardiovasc Surg. 2000;119:558-65.

33. Ma WG, Zheng J, Sun LZ, Elefteriades JA. Open stented grafts for frozen elephant trunk technique: technical aspects and current outcomes. Aorta (Stamford). 2015;3:122-35.

34. Ikonomidis JS. Do we have a novel, clinically applicable approach to spinal cord protection? J Thorac Cardiovasc Surg. 2015;149:586-7.

35. Hata M, Akiyama K, Hata H, Sezai A, Yoshitake I, Wakui S, et al. Early and midterm outcomes of quick proximal arch replacement with mild hypothermia and rapid rewarming for type A acute aortic dissection. J Thorac Cardiovasc Surg. 2013;146:119-23.

36. Sun LZ, Qi R, Zhu JM, Liu YM, Zheng J. Total arch replacement combined with stented elephant trunk implantation: a new "standard" therapy for type A dissection involving repair of the aortic arch? Circulation. 2011;123:971-8.

37. Easo J, Weigang E, Hölzl PP, Horst M, Hoffmann I, Blettner M, et al. Influence of operative strategy for the aortic arch in DeBakey type I aortic dissection: analysis of the German Registry for Acute Aortic Dissection Type A (GERAADA). Ann Cardiothorac Surg. 2013;2:175-80.

38. Wang J, Zhang L, Wang F, Liu L, Wang H. Prevalence, awareness, treatment, and control of hypertension in China: results from a national survey. Am J Hypertens. 2014;27:1355-61.

Key Words: aorta, thoracic/surgery, aortic dissection, blood vessel prosthesis, treatment outcome, mortality, Kaplan-Meier estimate

\section{Discussion}

Dr J. Ikonomidis (Charleston, SC). Congratulations on a very interesting and provocative study. I do have a few questions for you. First, in your manuscript you state that over the time period between April 2003 and November 2012, 832 patients with type A dissections were treated with total branched arch graft replacement with a frozen elephant trunk, and of those, only 104 had arch tears. This aggressive approach seems to fly in the face of the commonly held philosophy that we tend to adopt a more conservative approach to type A dissection repair unless our hand is forced. I wonder if you would care to comment on the justification for this aggressive repair strategy.

Dr Ma. Thank you for raising this very important issue on the extent of aortic resection in the setting of an acute dissection. During the study period, we had 832 patients with type A dissection who underwent this aggressive procedure, but we also had other patients who received a different operation. For this aggressive approach, in our previous study that was presented at this meeting last year we showed that neither the acute nor the chronic phase of aortic dissection affects the early mortality and morbidity of this operation. Instead, it was the malperfusion syndromes such as ischemia of the myocardium, the brain, the viscera, and the spinal cord that affected early mortality and morbidity.

In addition, we assume that the insertion of a frozen elephant trunk in the descending aorta helps to make the distal anastomosis stronger and reduces the risk of postoperative bleeding. This was supported by the low percentage of reexploration for bleeding in our series.

Dr Ikonomidis. Sure. My next question has to do with the timing of surgery. In your arch group of 104 patients, the median time to surgery was almost 5 days from the time of the onset of symptoms. In the non-arch group, 728 patients, the median time to surgery was almost 14 days.

Can you tell us a little bit more about these patients? How many of these patients were true acute type A dissections that came into your center, and did you really sit on them for 5 days before you operated on them? What is your treatment algorithm, and how many patients died waiting for surgery?

Dr Ma. Your question addresses another fundamentally important feature of our work. There was a delay in surgery in our series, and the main reason is that our center is the largest aortic referral center in the country. And the majority of patients, more than $80 \%$, were transferred from other places to us. It is difficult to estimate how many patients died before they reached our hospital.

Last year, a total of 626 patients presented to our emergency department. The mean duration of waiting for surgery was two days, and 80 patients died while waiting for surgery.

Dr Ikonomidis. Those numbers are staggeringly large. Very impressive indeed.

The last question I have has to do with one of the items on your table where in the entire series of 832 patients, you list only 24 as needing any type of sinus of Valsalva repair. Most of the type A dissections that I have treated have involved the sinuses, especially the noncoronary sinus, needing some sort of intervention. Please comment on the related findings in your series.

Dr Ma. Almost 50\% of our patients had root or valve involvement, but the percentage of valve repair was 
relatively low compared with those of valve or root replacement procedures. For those patients with root involvement, we would often treat them with aortic valve resuspension. The repair of the sinus of Valsalva was done by replacement of one or two cusps with a patch of vascular graft in most cases. As you can see (in slide 10), there were 256 patients who underwent a composite root replacement and 102 patients who had an aortic valve resuspension. Putting all these procedures together, that would be $49 \%$ of patients who had valve or root involvement. Thank you.

Dr A. Estrera (Houston, Tex). In a follow-up to Dr Ikonomidis' first question, over the past 8 years, we followed your team's work. You first presented the Sun procedure for type A dissection involving only the ascending aorta and showed excellent results. Then you followed that with another publication showing when the dissection started in the descending thoracic aorta and had retrograde type A dissection, you can use a Sun procedure with excellent results.

And then now you're showing a paper with a transverse arch tear with excellent results.

So the question is, when do you not use a Sun procedure since you demonstrated excellent results across the board?

Dr Ma. Dr Estrera, thank you very much. You have addressed a very important aspect of our work. As I mentioned, our center is the largest aortic referral center in China, and many easier patients may have already been picked up by remote or peripheral hospitals. In patients who had an entry tear located in the root or the ascending aorta but without involvement of the arch vessels, we would do a different procedure rather than the Sun operation. We have examined the percentage of patients who received a different operation. During the past 6 years, we had over 300 patients who received a hemiarch or ascending aortic replacement, or an isolated Bentall type operation.

Dr Estrera. And so while we have you on the podium, there were some comments I think it was earlier this morning about why it's so high, and why do you have so many dissections, and someone talked about blood pressure. I'd like to hear your comments on why it's so predominant. I mean, it's amazing the staggering numbers you guys do, over a thousand aortic operations per year. It's just impressive to me. Your comments.

Dr Ma. Yes, the young age of our patients and the predominance of hypertension are staggering. In this cohort of arch dissections, $85 \%$ of the patients have hypertension. I think this is due to the health care system in China, which does not provide the same level of care as in western countries. And due to the rapid socioeconomic and environmental changes that China is experiencing, many patients with hypertension do not receive good care and monitoring.

According to a publication in the American Journal of Hypertension last year, the estimated prevalence of hypertension in China was $29.6 \%$, which corresponds to 325 million patients.

Dr X. Sun (Beijing, China). I don't have any questions for Dr Ma, but I would like to answer the first professor's first question, the reason why the majority of our patients suffer from acute type A aortic dissection have undergone the total aortic arch replacement other than the hemiarch replacement. One reason is because the median age of our patients is pretty young. Compared with the patients in Western countries, there is 20 years difference. So we would like to replace the total arch because this life expectancy is longer.

And the second reason that we delivered our stent graft in the descending aorta is because there will be some patients who will face undergoing the second-stage procedure to replace the descending aorta and the thoracoabdominal aorta. So if the surgeon performed the first procedure with the stent graft in the descending aorta, it will be very easy to perform the second procedure to replace the thoracoabdominal aorta.

So that's why we have so many total aortic arch replacements.

Dr Ma. Yes. Because of the cultural differences and health care conditions, the majority of our patients are extremely unwilling to return for a second-stage operation on the downstream aorta. So we believe that given these circumstances, it is reasonable to perform an intervention on the descending aorta during the primary procedure. Thank you. 